\title{
Al-Ti-Containing Lightweight High-Entropy Alloys for Intermediate Temperature Applications
}

\author{
Minju Kang, Ka Ram Lim, Jong Woo Won, Kwang Seok Lee and Young Sang Na * \\ Korea Institute of Materials Science, 797 Changwondae-ro, Seongsan-gu, Changwon, \\ Gyeongnam 642-831, Korea; minju214@gmail.com (M.K.); krlim@kims.re.kr (K.R.L.); \\ jwwon@kims.re.kr (J.W.W.); ksl1784@kims.re.kr (K.S.L.) \\ * Correspondence: nys1664@kims.re.kr; Tel.: +82-55-280-3377
}

Received: 19 April 2018; Accepted: 8 May 2018; Published: 9 May 2018

\begin{abstract}
In this study, new high-entropy alloys (HEAs), which contain lightweight elements, namely $\mathrm{Al}$ and $\mathrm{Ti}$, have been designed for intermediate temperature applications. $\mathrm{Cr}, \mathrm{Mo}$, and $\mathrm{V}$ were selected as the elements for the Al-Ti-containing HEAs by elemental screening using their binary phase diagrams. AlCrMoTi and AlCrMoTiV HEAs are confirmed as solid solutions with minor ordered B2 phases and have superb specific hardness when compared to that of commercial alloys. The present work demonstrates the desirable possibility for substitution of traditional materials that are applied at intermediate temperature to Al-Ti-containing lightweight HEAs.
\end{abstract}

Keywords: high-entropy alloys; alloys design; lightweight alloys

\section{Introduction}

Recently, high-entropy alloys (HEAs) have attracted considerable attention because of their extraordinary properties [1-10], and numerous HEAs have been reported with various compositions [1-10]. Three major HEAs are CoCrFeMnNi alloy which has potential applications in cryogenic environments [5,6], refractory $\mathrm{VNbMoTaW}$ alloy for high-temperature structural applications [7,8], and $\mathrm{AlCoCrFeNi}$ alloy which maintains high strength up to intermediate temperatures $[9,10]$. AlCoCrFeNi HEA is relatively lightweight and has excellent specific strength around intermediate temperatures. It is a possible alternative for Ti alloys or wrought superalloys such as Inconel 718 [9,10]. Additional weight reduction can improve the competitiveness of the lightweight HEAs; therefore, we attempted to develop new HEAs that contain lightweight elements, namely $\mathrm{Al}$ and Ti.

Most HEAs are developed by a trial-and-error approach based on the effects such as mixing enthalpy and valence electron concentration (VEC) [11,12]. This conventional method is not effective when developing HEAs with a new combination of elements among numerous possibilities. The CALPHAD (Computer Coupling of Phase Diagrams and Thermochemistry) approach may be the best way for designing new HEAs because of its capability in predicting the phase stability [13-16]. However, the application of CALPHAD to the design of new HEAs is challenging because of the lack of a reliable thermodynamic database to cover the entire composition range [13-15]. F. Zhang et al. [17] reported a new approach to design new multi-component FCC HEAs by binary phase diagrams. The FCC single phase formation in the CoCrFeMnNi HEA was predicted using this approach [17]. This method is effective at finding "matching elements" that form a single solid solution and is suitable for designing novel HEAs.

In this work, we sought to design lightweight HEAs, which contain lightweight elements, namely $\mathrm{Al}$ and $\mathrm{Ti}$, by using binary phase diagrams. Seven HEAs containing $\mathrm{Al}$ and Ti were designed and their mechanical properties were compared with those of commercial alloys. 


\section{Materials and Methods}

The selection of candidate elements was conducted based on their binary phase diagrams. The details regarding the design of the Al-Ti-containing lightweight HEAs are described in Section 3.1.

The aforementioned Al-Ti-containing lightweight HEAs were fabricated by vacuum plasma arc melting (PAM) with high-purity elements. The HEA button ingots were re-melted 4 to 5 times in a melting furnace for the homogenization. The HEA plates were fabricated by vacuum induction melting using a graphite mold. The microstructures of the HEAs were analyzed by optical microscopy (OM), FE-SEM (model: SU-6600, HITACHI), and transmission electron microscopy (TEM, model: Tecnai F20, FEI). The TEM samples were prepared using focused ion beam (FIB). The crystal structure of the material was examined by $\mathrm{X}$-ray diffraction $(\mathrm{XRD})$ measurements on the as-casted material using a MXP21VAHF diffractometer with a $\mathrm{CuK} \alpha$ radiation source (model: D/Max-2500VL/PC, RIGAKU). The Vickers hardness tests were carried out using a conventional indenter with a load of $2.94 \mathrm{~N}$ for $15 \mathrm{~s}$. A minimum 10 tests were carried out on specimen.

\section{Results and Discussion}

\subsection{Selection of Candidate Elements Based on Their Binary Phase Diagrams}

To design lightweight HEAs, we selected $\mathrm{Al}$ and Ti as the basic elements owing to their low density. The key idea of designing new HEAs using their binary phase diagrams is finding elements that mix. Therefore, the solubility of $\mathrm{Al}$ and Ti should be investigated first. Figure 1 shows the Al-Ti phase diagram [18]. It is very complex, and numerous intermediate ordered phases exist. However, $\beta$-Ti (BCC phase) and $\alpha-\mathrm{Ti}$ (HCP phase) appear in the Ti-rich region as a solid solution. These solid solution regions suggest the possibility of the formation of single solid solution. Therefore, the lightweight elements, $\mathrm{Al}$ and $\mathrm{Ti}$, could be the basic elements for lightweight HEAs.

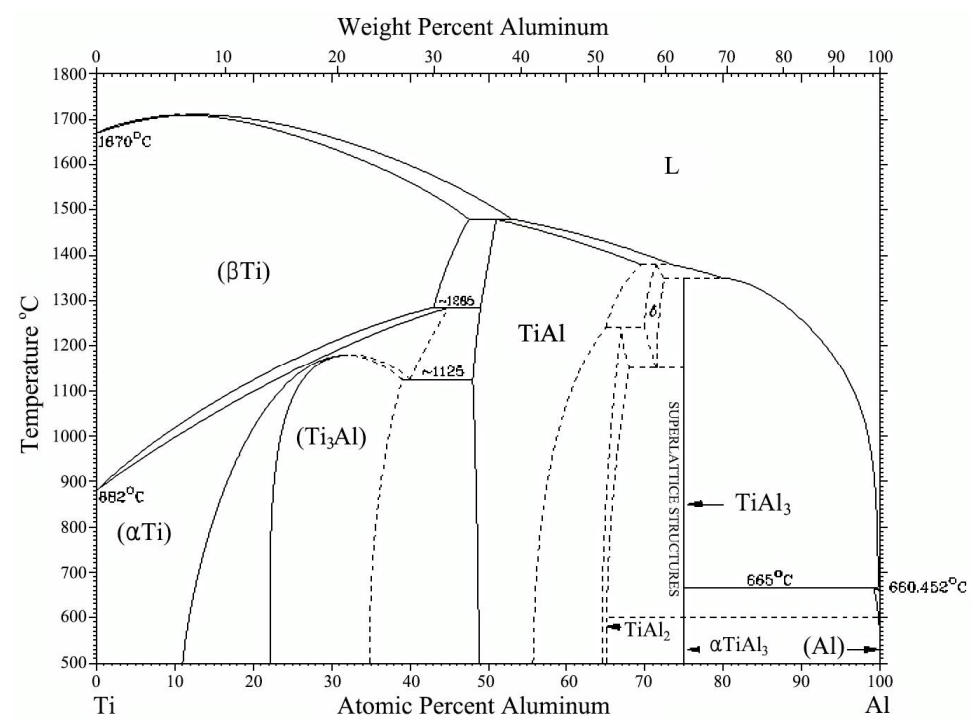

Figure 1. Al-Ti phase diagram [18]. It has solid solution region within a certain temperature and composition range that suggest the possibility of the formation of single solid solution.

The design of the Al-Ti-containing HEAs consisted of three steps. In the first step, the candidate elements were selected from various Ti-X binary phase diagrams wherein " $X$ " represents elements that form homogeneous solid solution with Ti within a certain temperature range [18]. In the second step, a second series of candidate elements were selected from various Y-Al binary phase diagrams, wherein " $Y$ " represents elements that show adequate solubility in Al within a certain composition and 
temperature range. The final step was the selection of the final candidate elements from the $\mathrm{X}-\mathrm{Y}$ binary phase diagrams.

From the Ti- $X$ binary phase diagrams, we found 8 candidate elements, $\mathrm{Cr}, \mathrm{Hf}, \mathrm{Mo}, \mathrm{Nb}, \mathrm{Ta}, \mathrm{V}$, $\mathrm{W}$, and $\mathrm{Zr}$, in which each had a solid solution region in a certain range [18]. Figure 2 shows the Ti- $\mathrm{X}$ $(\mathrm{X}=\mathrm{Cr}, \mathrm{Hf}, \mathrm{Mo}, \mathrm{Nb}, \mathrm{Ta}, \mathrm{V}, \mathrm{W}$, or $\mathrm{Zr}$ ) binary phase diagrams. All elements had a large area of solid solution within a certain temperature range, and all the homogeneous solid solution phases had BCC crystalline structure, indicated in green (Figure 2).
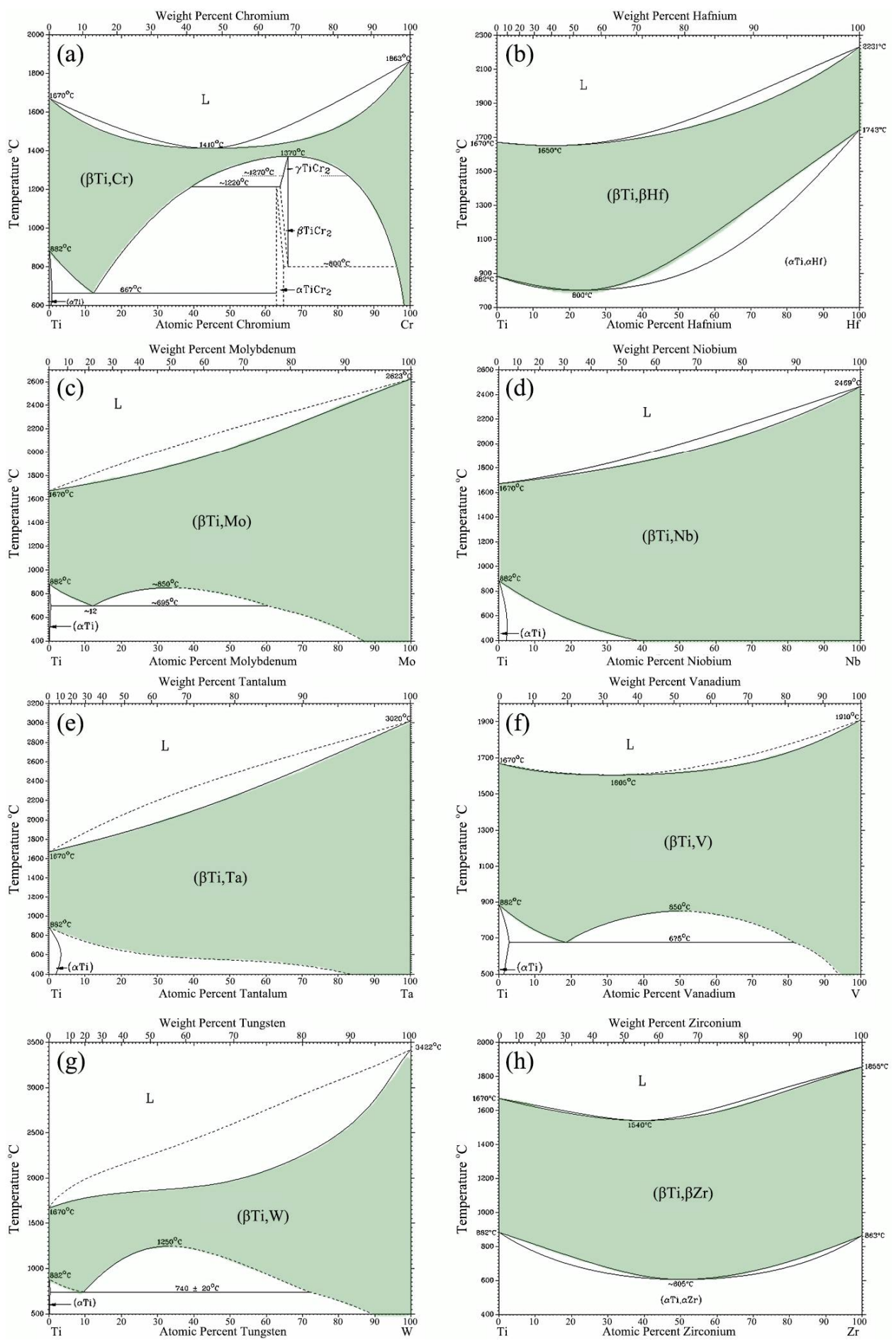

Figure 2. Ti-X phase diagrams where " $\mathrm{X}$ " is (a) Cr; (b) Hf; (c) Mo; (d) Nb; (e) Ta; (f) V; (g) W; and (h) Zr [18]. 
The next step consisted of finding a second series of candidate elements. Their binary phase diagrams are shown in the supplementary data (Figure S1). 6 candidate elements, Cr, Hf, Mo, Nb, V, and $\mathrm{Zr}$, were chosen from the $\mathrm{Y}$-Al binary phase diagrams. These elements are not form solid solution in all composition ranges, although the solid solutions contain Y's own crystalline structure (BCC) at a certain temperature and composition range. Among the 6 candidates, $\mathrm{Nb}$ and $\mathrm{Zr}$ were removed because they form solid solution in very restricted range.

From the first and second steps, $\mathrm{Cr}, \mathrm{Hf}, \mathrm{Mo}$, and $\mathrm{V}$ were selected. To select the final candidate elements, the binary phase diagrams between these elements were investigated. Hf-Cr, Hf-Mo, and Hf-V showed complex phase diagrams, which could have possibly formed some intermediate ordered phases (supplementary data, Figure S2). Therefore, Cr, Mo, and V were selected as the elements for the Al-Ti-containing HEAs.

\subsection{Microstructure of the Al-Ti-Containing HEAs}

Ternary, quaternary, and quinary HEAs were designed by adding the selected elements to Al-Ti. Seven HEAs, numbered \#1 to \#7, were fabricated and their compositions are detailed in Table 1 . The XRD profiles of the Al-Ti-containing HEAs are shown in Figure 3. The AlCrMoTi (\#4) and AlCrMoTiV (\#7) had a single BCC structure, and ordered BCC peaks appeared for the other HEAs.

Table 1. Valence electron concentration (VEC), atomic size difference ( $\delta$ ), and enthalpy of mixing $\left(\Delta \mathrm{H}_{\mathrm{mix}}\right)$ of designed HEAs.

\begin{tabular}{ccccc}
\hline & Alloys & VEC & $\boldsymbol{\delta}(\mathbf{\%})$ & $\boldsymbol{\Delta} \mathbf{H}_{\text {mix }}(\mathbf{k J} / \mathbf{m o l})$ \\
\hline$\# 1$ & AlCrTi & 4.33 & 5.49 & -20.96 \\
$\# 2$ & AlMoTi & 4.33 & 1.77 & -17.44 \\
$\# 3$ & AlTiV & 4.00 & 3.42 & -21.33 \\
$\# 4$ & AlCrMoTi & 4.75 & 4.76 & -14.00 \\
$\# 5$ & AlCrTiV & 4.50 & 5.03 & -16.75 \\
$\# 6$ & AlMoTiV & 4.50 & 3.02 & -14.25 \\
$\# 7$ & AlCrMoTiV & 4.80 & 4.51 & -12.16 \\
\hline
\end{tabular}

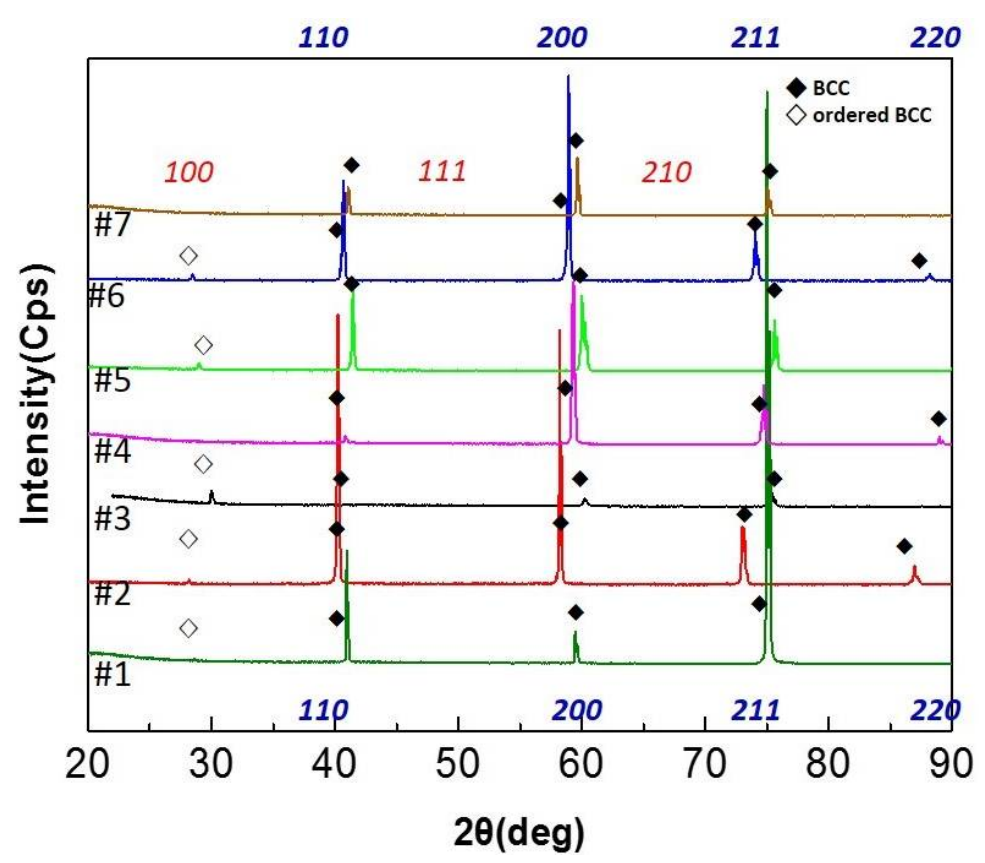

Figure 3. The XRD patterns of Al-Ti-containing HEAs. 
The microstructures of AlCrMoTi (\#4) and AlCrMoTiV (\#7) which had a single BCC structure, are shown in Figure 4a,b. Both showed a dendritic morphology, and the dendritic growth was suppressed by the addition of V. The TEM analysis was performed for AlCrMoTiV (\#7), and the results are shown in Figure 4c,d. Figure 4c is bright field image of AlCrMoTiV (\#7) and Figure 4d is the diffraction pattern taken from $[001]_{\mathrm{B} 2 / \mathrm{BCC}}$ zone axis of Figure 4c. Although the XRD results demonstrate that it is a single BCC structure, diffraction pattern reveals (100) superlattice reflections marked with red-dotted circle that indicate an ordered B2 phase. Nano-scale B2 phases were observed; however, it was not detected by the XRD owing to their small fraction and size. Because AlCrMoTiV (\#7) contained minor ordered precipitates, it could be defined as an ordered solid solution [19].
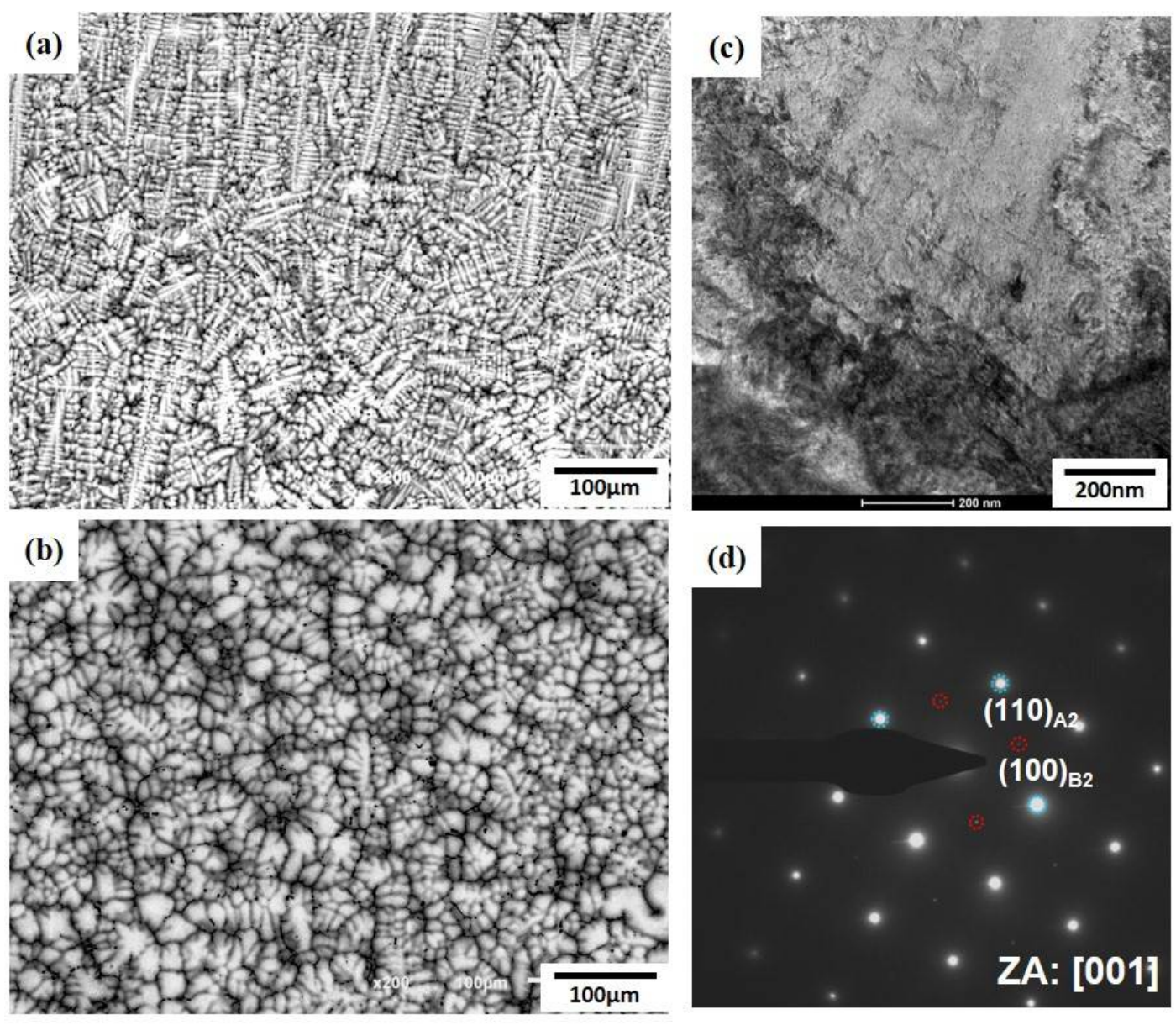

Figure 4. Microstructures of (a) AlCrMoTi and (b) AlCrMoTiV. Both have dendritic morphology. (c) bright field image and (d) diffraction pattern of AlCrMoTiV.

One of the physical properties of HEAs is the high-entropy effect [20]. The solid solution is stabilized because of the high configurational entropy [20,21], and this effect increases with an increased number of elements [20]. This trend can be observed in our work. As the number of elements increased from ternary to quinary, the phases progressively became simpler. The high-entropy effect is dominant at high temperatures according to $\mathrm{G}=\mathrm{H}-\mathrm{TS}$, where $\mathrm{G}$ is Gibbs free energy, $\mathrm{H}$ is enthalpy, $T$ is temperature, and $S$ is entropy $[20,21]$. Thus, this HEA can exist as a solid solution at elevated temperatures, even though a small fraction of the B2 phase existed in an as-cast state at room temperature. 


\subsection{Application of Empirical Parameters}

The empirical parameters for the HEAs originated from the classic Hume-Rothery rules [22,23]. Guo et al. [24] reported that $-22 \leq \Delta \mathrm{H}_{\mathrm{mix}} \leq 7 \mathrm{~kJ} / \mathrm{mol}$, and $\delta \leq 8.5 \%$ are required for the sole simple phases (i.e., FCC, BCC, and their mixtures, including both ordered/disordered cases). Zhang et al. [19] proposed $-15 \leq \Delta \mathrm{H}_{\text {mix }} \leq 5 \mathrm{~kJ} / \mathrm{mol}$ and $\delta \leq 6.5 \%$, whereas Yang et al. [12] proposed $\delta \leq 6.6 \%$. In the case of VEC, $8<$ VEC and VEC $<6.87$ were suggested for the single FCC and BCC structures, respectively [20]. These parameters were statistically determined; therefore, there are differences and exceptions depending on the work $[12,19,22,25]$.

The empirical parameters, valence electron concentration (VEC), atomic size difference $(\delta)$, and enthalpy of mixing $\left(\Delta \mathrm{H}_{\text {mix }}\right)$ of the designed HEAs were calculated and are shown in Table 1 and Figure 5 [22]. The VEC and $\delta$ values satisfied the existing criteria. However, the $\Delta \mathrm{H}_{\text {mix }}$ values were positioned relatively below the alloys which form solid solutions (Figure 5b). All the HEAs satisfy Guo's criterion although only AlCrMoTi (\#4), AlMoTiV (\#6), and AlCrMoTiV (\#7) satisfy Zhang's criterion. The microstructural analysis demonstrates that AlCrMoTi (\#4) and AlCrMoTiV (\#7) are ordered solid solutions; the empirical parameters of HEAs in present work agree with previous research and support the idea that using the binary phase diagrams can be a solution to screen the proper candidate elements for the design of novel HEAs.
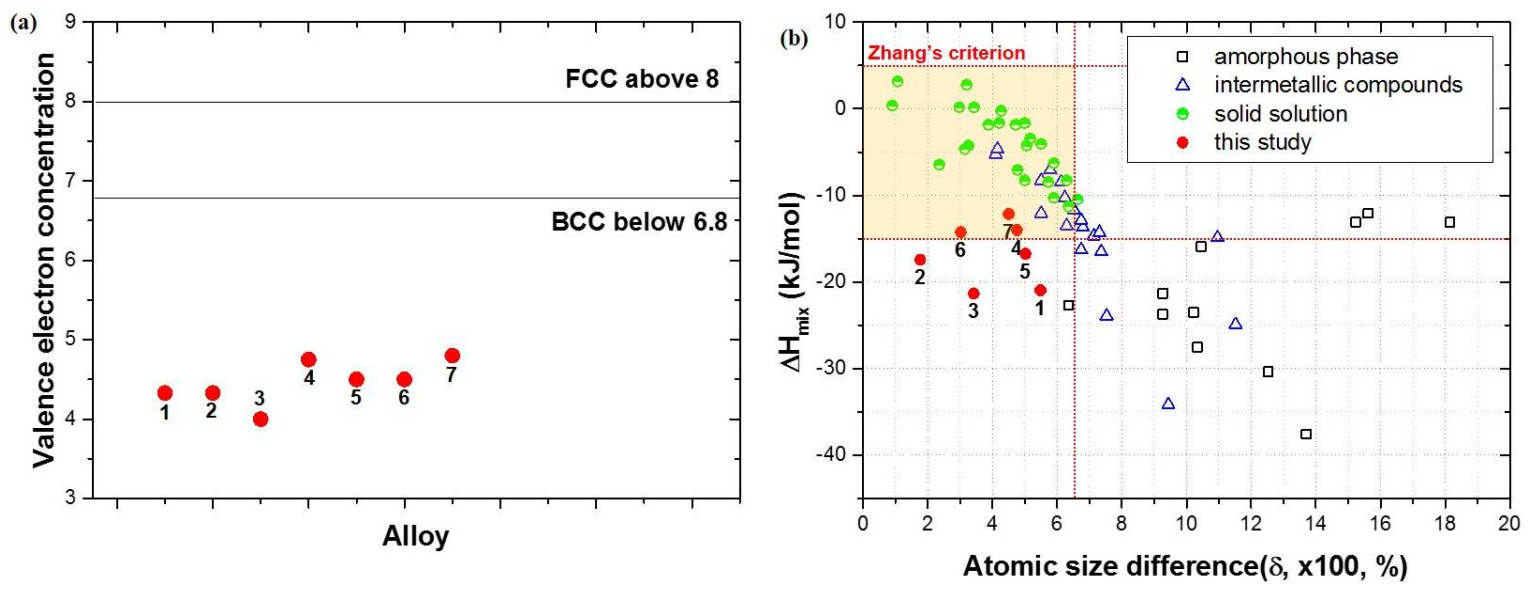

Figure 5. (a) VEC and (b) $\delta-\Delta \mathrm{H}_{\text {mix }}$ plot of Al-Ti-containing HEAs. Yellow colored regions highlight Zhang's criterion [19] for single phase to form.

\subsection{Specific Hardness of the Al-Ti-Containing HEAs}

It has been reported that HEAs have a severe lattice distortion owing to the atomic size differences of elements, which induces solid solution strengthening [25]. Figure 6 shows the relationship between the hardness and $\delta$. The hardness varied across the $\delta$ values. Moreover, Figure $6 \mathrm{~b}$ clearly shows the hardness variation with the addition of $\mathrm{Cr}, \mathrm{Mo}$, and $\mathrm{V}$. The hardness increased remarkably with the addition of Cr. The atomic radius of $\mathrm{Cr}$ is $1.25 \AA$ which is quite different than the others [24]; this causes further severe lattice distortion.

The hardness of the AlCrMoTi (\#4) and AlCrMoTiV (\#7) solid solutions were compared with that of other HEAs and commercial alloys and is summarized in Table 2 [26-31]. The hardness of the AlCrMoTi (\#4) and AlCrMoTiV (\#7) were $606 \pm 11$ and $556 \pm 25 \mathrm{HV}$, respectively. These values are $17 \%$ and $7 \%$ higher than that of the AlCoCrFeNi HEA, which is representative of HEAs for intermediate temperature applications [9]. The theoretical densities are also lower than that of the AlCoCrFeNi HEA, so the specific hardnesses were $30 \%$ and $19 \%$ higher than that of the AlCoCrFeNi HEA. Furthermore, the specific hardness of the HEAs in the present work are considerably higher than that of competitive conventional alloy systems. The AlCrMoTi (\#4) showed a $29 \%$ improved specific hardness when compared with that of Ti-6Al-4V alloy, which is an alloy that is commonly 
used for intermediate temperature applications. It is expected that a great improvement in the hardness can accomplish the weight lightening through the gage reduction of machineries despite their higher density when compared to that of the Ti-6Al-4V alloy. Further research on the fine-tuning of the elemental composition for lighter and cheaper alloys as well as a detailed microstructural and high-temperature property analysis could open a new path toward lightweight HEAs for intermediate temperature applications.
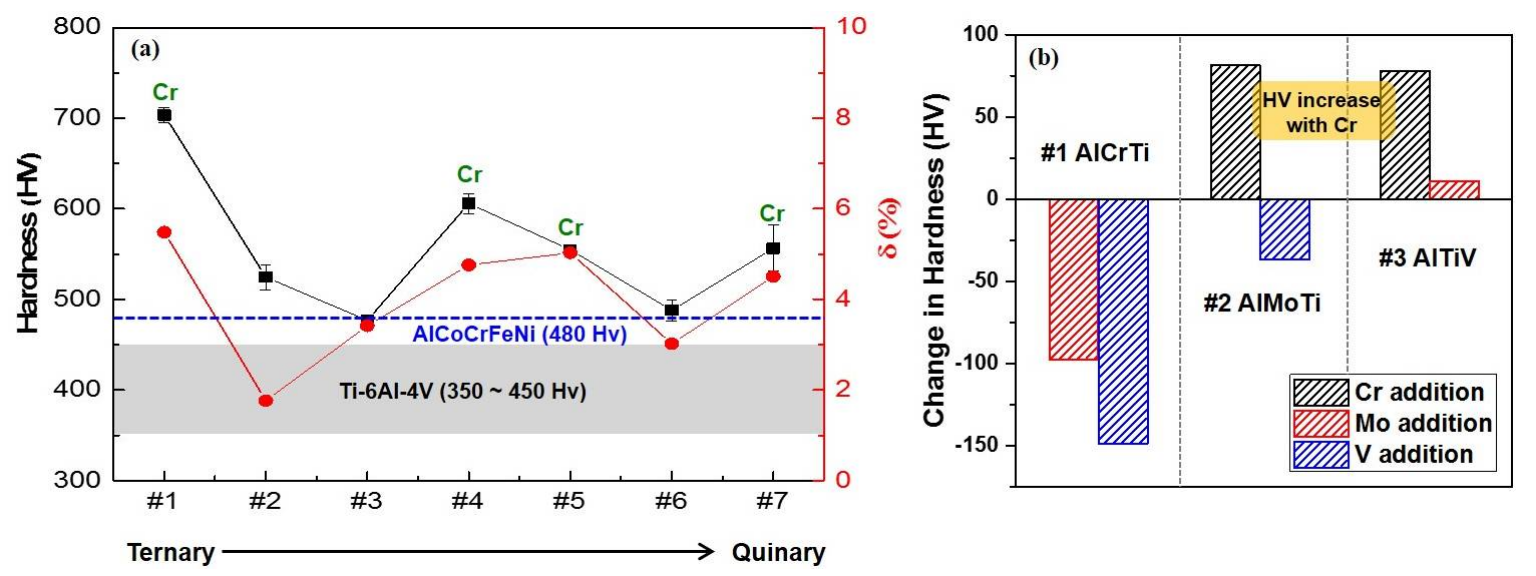

Figure 6. (a) Relationship between the hardness and atomic size difference; (b) hardness variation with the $\mathrm{Cr}$, Mo, and V addition to ternary HEAs. The hardness increases remarkably with the $\mathrm{Cr}$ addition.

Table 2. Comparison of specific hardness of HEAs with other alloys.

\begin{tabular}{|c|c|c|c|}
\hline Alloys & Hardness (HV) & Theoretical Density $\left(\mathrm{g} / \mathrm{cm}^{3}\right)$ & Specific Hardness $\left(\mathrm{HV} / \mathrm{g} / \mathrm{cm}^{3}\right)$ \\
\hline AlCrMoTi (\#4) & 606 & 6.01 & 100.83 \\
\hline AlCrMoTiV (\#7) & 556 & 6.00 & 92.67 \\
\hline $\mathrm{AlCoCrFeNi}[26]$ & 520 & 6.70 & 77.61 \\
\hline AlCoCrCuFeNi [27] & 400 & 7.02 & 56.98 \\
\hline $\mathrm{Al}_{0.5} \mathrm{CoCrCuFeNiV} \mathrm{[28]}$ & 640 & 7.27 & 88.03 \\
\hline Ti-6Al-4V [29] & 346 & 4.43 & 78.10 \\
\hline Ti-6242 [30] & 339 & 4.54 & 74.67 \\
\hline Inconel 718 [31] & 355 & 8.18 & 43.40 \\
\hline
\end{tabular}

\section{Conclusions}

In summary, HEAs which contained $\mathrm{Al}$ and Ti were designed based on their binary phase diagrams. This approach is powerful for screening candidate elements for novel HEAs. The candidate elements that were selected formed a solid solution within a certain temperature and composition range. The high-entropy effect is enhanced with an increased number of elements; therefore, the AlCrMoTi and AlCrMoTiV HEAs are verified to be solid solutions with a minor ordered B2 phase. These HEAs have a superb specific hardness when compared to that of Ti-6Al-4V and Inconel 718 alloys and show promise as future substitutes for Ti alloys for intermediate temperature structural applications. Furthermore, fine-tuning of the elemental composition of HEAs can lead to the development of novel light-weight HEAs.

Supplementary Materials: The following are available online at http:/ / www.mdpi.com/1099-4300/20/5/355/s1, Figure S1: Y-Al phase diagrams where " $\mathrm{Y}$ " is (a) $\mathrm{Cr}$, (b) $\mathrm{Hf}$, (c) $\mathrm{Mo}$, (d) $\mathrm{Nb}$, (e) $\mathrm{V}$, and (f) $\mathrm{Zr}$ [18]. Figure S2: (a) $\mathrm{Hf}-\mathrm{Cr}$, (b) Cr-Mo, (c) Cr-V, (d) Hf-Mo, (e) Hf-V, and (f) Mo-V binary phase diagrams [18]. Cr, Mo, and V were selected which have simple phase diagrams.

Author Contributions: M.K., K.R.L., J.W.W. and Y.S.N. conceived and designed the experiments; M.K. and K.R.L. performed the experiments and analyzed the data; K.S.L. and Y.S.N. contributed reagents/materials/analysis tools; M.K. wrote the paper. 
Acknowledgments: This study was supported financially by Fundamental Research Program (PNK5610) of the Korean Institute of Materials Science (KIMS), and by the Future Material Discovery Project of the National Research Foundation of Korea (NRF) funded by the Ministry of Science, ICT and Future Planning (MSIP) of Korea (NRF-2016M3D1A1023534).

Conflicts of Interest: The authors declare no conflict of interest.

\section{References}

1. Cantor, B.; Chang, I.T.H.; Knight, P.; Vincent, A.J.B. Microstructural development in equiatomic multicomponent alloys. Mater. Sci. Eng. A 2004, 375-377, 213-218. [CrossRef]

2. Manzoni, A.M.; Singh, S.; Daoud, H.M.; Popp, R.; Völkl, R.; Glatzel, U.; Wanderka, N. On the path to optimizing the Al-Co-Cr-Cu-Fe-Ni-Ti high entropy alloy family for high temperature applications. Entropy 2016, 18, 104. [CrossRef]

3. He, J.Y.; Wang, H.; Huang, H.L.; Xu, X.D.; Chen, M.W.; Wu, Y.; Liu, X.J.; Nieh, T.G.; An, K.; Lu, Z.P. A precipitation-hardened high-entropy alloy with outstanding tensile properties. Acta Mater. 2016, 102, 187-196. [CrossRef]

4. Chen, Y.; Li, Y.; Cheng, X.; Wu, C.; Cheng, B.; Xu, Z. The Microstructure and Mechanical Properties of Refractory High-Entropy Alloys with High Plasticity. Materials 2018, 11, 208. [CrossRef] [PubMed]

5. Gali, A.; George, E.P. Tensile properties of high- and medium-entropy alloys. Intermetallics 2013, 39, 74-78. [CrossRef]

6. Gludovatz, B.; Hohenwarter, A.; Catoor, D.; Chang, E.H.; George, E.P.; Ritchie, R.O. A fracture-resistant high-entropy alloy for cryogenic applications. Science 2014, 345, 1153-1158. [CrossRef] [PubMed]

7. Han, Z.D.; Chen, N.; Zhao, S.F.; Fan, L.W.; Yang, G.N.; Shao, Y.; Yao, K.F. Effect of Ti additions on mechanical properties of $\mathrm{NbMoTaW}$ and $\mathrm{VNbMoTaW}$ refractory high entropy alloys. Intermetallics 2017, 84, 153-157. [CrossRef]

8. Senkov, O.N.; Wilks, G.B.; Scott, J.M.; Miracle, D.B. Mechanical properties of $\mathrm{Nb}_{25} \mathrm{Mo}_{25} \mathrm{Ta}_{25} \mathrm{~W}_{25}$ and $\mathrm{V}_{20} \mathrm{Nb}_{20} \mathrm{Mo}_{20} \mathrm{Ta}_{20} \mathrm{~W}_{20}$ refractory high entropy alloys. Intermetallics 2011, 19, 698-706. [CrossRef]

9. Lim, K.R.; Lee, K.S.; Lee, J.S.; Kim, J.Y.; Chang, H.J.; Na, Y.S. Dual-phase high-entropy alloys for high-temperature structural applications. J. Alloys Compd. 2017, 728, 1235-1238. [CrossRef]

10. Lu, Y.; Dong, Y.; Guo, S.; Jiang, L.; Kang, H.; Wang, T.; Wen, B.; Wang, Z.; Jie, J.; Cao, Z.; et al. A promising new class of high-temperature alloys: Eutectic high-entropy alloys. Sci. Rep. 2014, 4, 6200. [CrossRef] [PubMed]

11. Jin, X.; Zhou, Y.; Zhang, L.; Du, X.; Li, B. A new pseudo binary strategy to design eutectic high entropy alloys using mixing enthalpy and valence electron concentration. Mater. Des. 2018, 143, 49-55. [CrossRef]

12. Yang, X.; Zhang, Y. Prediction of high-entropy stabilized solid-solution in multi-component alloys. Mater. Chem. Phys. 2012, 132, 233-238. [CrossRef]

13. Choi, W.M.; Jung, S.; Jo, Y.H.; Lee, S.; Lee, B.J. Design of new face-centered cubic high entropy alloys by thermodynamic calculation. Met. Mater. Int. 2017, 23, 839-847. [CrossRef]

14. Zhang, C.; Zhang, F.; Chen, S.; Cao, W. Computational thermodynamics aided high-entropy alloy design. JOM 2012, 64, 839-845. [CrossRef]

15. Gao, M.C.; Alman, D.E. Searching for Next Single-Phase High-Entropy Alloy Compositions. Entropy 2013, 15, 4504-4519. [CrossRef]

16. Ma, D.; Yao, M.; Pradeep, K.G.; Tasan, C.C.; Springer, H.; Raabe, D. Phase stability of non-equiatomic CoCrFeMnNi high entropy alloys. Acta Mater. 2015, 98, 288-296. [CrossRef]

17. Zhang, F.; Zhang, C.; Chen, S.L.; Zhu, J.; Cao, W.S.; Kattner, U.R. An understanding of high entropy alloys from phase diagram calculations. Calphad 2014, 45, 1-10. [CrossRef]

18. ASM Handbook. Alloy Phase Diagrams; ASM International: Novelty, OH, USA, 1992.

19. Zhang, Y.; Zhou, Y.J.; Lin, J.P.; Chen, G.L.; Liaw, P.K. Solid-Solution Phase Formation Rules for Multi-component Alloys. Adv. Eng. Mater. 2008, 10, 534-538. [CrossRef]

20. Tsai, M.H.; Yeh, J.W. High-Entropy Alloys: A Critical Review. Mater. Res. Lett. 2014, 2, 107-123. [CrossRef]

21. Yeh, J.W. Alloy design strategies and future trends in high-entropy alloys. JOM 2013, 65, 1759-1771. [CrossRef]

22. Guo, S.; Ng, C.; Lu, J.; Liu, C.T. Effect of valence electron concentration on stability of FCC or bcc phase in high entropy alloys. J. Appl. Phys. 2011, 109, 103505. [CrossRef] 
23. Singh, P.; Sharma, A.; Smimov, A.V.; Diallo, M.S.; Ray, P.K.; Balasubramanian, G.; Johnson, D.D. Design of high-strength refractory complex solid-solution alloys. npj Comput. Mater. 2018, 4, 16. [CrossRef]

24. Guo, S.; Liu, C.T. Phase stability in high entropy alloys: Formation of solid-solution phase or amorphous phase. Prog. Nat. Sci. 2011, 21, 433-446. [CrossRef]

25. Yeh, J.W.; Chang, S.Y.; Hong, Y.D.; Chen, S.K.; Lin, S.J. Anomalous decrease in X-ray diffraction intensities of Cu-Ni-Al-Co-Cr-Fe-Si alloy systems with multi-principal elements. Mater. Chem. Phys. 2007, 103, 41-46. [CrossRef]

26. Ma, S.G.; Zhang, Y. Effect of $\mathrm{Nb}$ addition on the microstructure and properties of AlCoCrFeNi high-entropy alloy. Mater. Sci. Eng. A 2012, 532, 480-486. [CrossRef]

27. Tong, C.J.; Chen, M.R.; Chen, S.K.; Yeh, J.W.; Shun, T.T.; Lin, S.J.; Chang, S.Y. Mechanical Performance of the $\mathrm{Al}_{\mathrm{x}} \mathrm{CoCrCuFeNi}$ High-Entropy Alloy System with Multiprincipal Elements. Metall. Mater. Trans. A 2005, 36, 1263-1271. [CrossRef]

28. Chen, M.R.; Lin, S.J.; Yeh, J.W.; Chen, S.K.; Huang, Y.S.; Chuang, M.H. Effect of Vanadium Addition on the Microstructure, Hardness, and Wear Resistance of $\mathrm{Al}_{0.5} \mathrm{CoCrCuFeNi}$ High-Entropy Alloy. Metall. Mater. Trans. A 2006, 37, 1363-1369. [CrossRef]

29. Niinomi, M. Mechanical properties of biomedical titanium alloys. Mater. Sci. Eng. 1998, 243, 231-236. [CrossRef]

30. Shen, W.; Soboyejo, A.B.O.; Soboyejo, W.O. Microstructural Effects on Fatigue and Dwell-Fatigue Crack Growth in $\alpha / \beta$ Ti-6Al-2Sn-4Zr-2Mo-0.1Si. Metall. Mater. Trans. A 2004, 35, 163-187. [CrossRef]

31. Li, H.Z.; Zeng, H.; Chen, X.Q. An experimental study of tool wear and cutting force variation in the end milling of Inconel 718 with coated carbide inserts. J. Mater. Process. Technol. 2006, 180, 296-304. [CrossRef]

(C) 2018 by the authors. Licensee MDPI, Basel, Switzerland. This article is an open access article distributed under the terms and conditions of the Creative Commons Attribution (CC BY) license (http:/ / creativecommons.org/licenses/by/4.0/). 